\title{
THE CENTRAL FORCE WATER MODEL AT THE ELECTROLYTE-ELECTRODE INTERFACE: AN INTEGRAL EQUATION APPROACH*
}

\author{
Martin Vossen, Frank Forstmann, Andreas Krämer \\ Institut für Theoretische Physik \\ Freie Universität Berlin \\ Arnimallee 14, D-14195 Berlin, Germany
}

Received September 12, 1995

\begin{abstract}
The central force water model is well suited for integral equation methods. At the electrode surface we find water molecules arranged in an ice-like structure with a surface dipole pointing towards the liquid and a negative surface potential $-0.11 \mathrm{~V}$ at zero electrode charge. We find an asymmetric differential capacitance due to the water structure. Added $\mathrm{Na}^{+}$and $\mathrm{Cl}^{-}$ions do not destroy the water structure. Only the small $\mathrm{Na}^{+}$can penetrate the structured water layer at high negative electrode charge.
\end{abstract}

\section{Introduction}

The central force water model is capable of representing the steric structure of the water molecules, the hydrogen bonds, the molecular charge distribution and part of the molecular polarizability. It is defined as a 1:2 mixture of oxygen and hydrogen atoms interacting via spherical effective potentials and bearing effective partial charges. The potential parameters have been optimized in simulations fitting e.g. neutron diffraction data. The central force spherical potentials are especially adapted for a statistical mechanical treatment of the system by integral equation methods. The mixture can be supplemented by spherically interacting ions to study electrolytes. We present here results for pure water and a sodium chloride solution at an electrode wall.

\section{The model and the method of calculation}

The central force water model was proposed by Stillinger, Lemberg and Rahman $[3,4,5]$. The effective potentials contain Coulombic parts, repulsive terms of high powers of $r$ and exponentially decaying attractive parts of longer range. The long range $\mathrm{H}-\mathrm{H}$ interaction is repulsive and adjusted in order to form a minimum for the second hydrogen atom at the angular position in the hydrogen molecule and to push the third hydrogen atom into

${ }^{*}$ This article has been submitted on the International Workshop on Statistical Physics \& Condensed Matter Theory, which was held in Lviv (Ukraine) in September 11-14, 1995. 
the hydrogen bond position. The many parameters have been optimized in molecular dynamics (MD) simulations. We have given the parameters in our paper [1].

The added ions interact via Coulomb potentials and Lenard Jones contributions with oxygen and hydrogen. We have fitted the parameters [2] to quantum mechanical ab initio calculations of Kistenmacher et al. [6]. The interactions between the ions are taken from [7] and [8]. All parameters can be found in [2].

For the above defined mixture of interacting charged atoms we calculate the bulk correlation functions from the Ornstein-Zernike equation

$$
h_{\alpha \beta}(r)=c_{\alpha \beta}(r)+\sum_{\gamma} \rho_{\gamma} \int d \mathbf{r}^{\prime} h_{\alpha \gamma}\left(r^{\prime}\right) c_{\gamma \beta}\left(\left|\mathbf{r}-\mathbf{r}^{\prime}\right|\right)
$$

together with the closure relation

$$
\ln \left[1+h_{\alpha \beta}(r)\right]=-\frac{1}{k_{B} T} u_{\alpha \beta}(r)+h_{\alpha \beta}(r)-c_{\alpha \beta}(r)-B_{\alpha \beta}(r) .
$$

$h_{\alpha \beta}(r)$ is the total and $c_{\alpha \beta}(r)$ the direct correlation function, $u_{\alpha \beta}(r)$ the interaction potential between particles of kinds $\alpha$ and $\beta . \rho_{\alpha}$ is the number density, $k_{B}$ BoltzmannTs constant. The bridge function $B_{\alpha \beta}(r)$, which would make equations (1) and (2) exact, is not known exactly and has to be approximated. The $\mathrm{HNC}$ approximation, which puts $B_{\alpha \beta}=0$, is not successful in reproducing characteristic features of the water correlations related to the hydrogen bonds [9]. We have developed bridge functions for the central force water model [1] similar to those proposed by Ichiye et al. [10] derived from reference hard sphere systems. The $\mathrm{H}-\mathrm{H}$ bridge function is taken attractive in order to improve the $\mathrm{H}-\mathrm{H}$ coordination. The bridge function usually counterbalances an overestimation of the long range part of the potential by the HNC approximation. Because this long range part is repulsive for $\mathrm{H}-\mathrm{H}$, an attractive bridgefunction makes sense.

Equations (1) and (2) are then solved by simple iteration with small mixing between old and new solutions. The long range Coulomb forces require a special careful treatment. The densities $\rho_{O}=0.03345 \AA^{-3}$ and $\rho_{H}=0.06690 \AA^{-3}$ represent $1 \mathrm{gcm}^{-3}$ of $\mathrm{H}_{2} \mathrm{O}$, the concentration of $\mathrm{NaCl}$ is 0.01 molar and the temperature is taken $\mathrm{T}=300 \mathrm{~K}$. figure 1 shows the bulk pair distribution functions $g_{\alpha \beta}(r)=1+h_{\alpha \beta}(r)$ for pure water. The comparison with the MD results, which are very close to neutron diffraction curves,demonstrates that the characteristic features of the water structure are well represented.figure 2 and figure 3 indicate the solvation structure around the ions. The running coordination numbers

$$
N_{\alpha \beta}(r)=4 \pi \rho_{\beta} \int_{0}^{r} d x x^{2} g_{\alpha \beta}(x)
$$

give an impression of the solvation shell. 6.5 water molecules in the first shell around $\mathrm{Na}^{+}$are in agreement with simulations, while the shell around $\mathrm{Cl}^{-}$appears too large probably due to potential parameters which make $\mathrm{Cl}^{-}$too big. The input to the calculations of the distributions near the electrode are the bulk direct correlation functions, which for pure water are shown in figure 4 . We compare our direct correlation functions to those of Haymet [22], who used only slightly changed interaction potentials and different bridge functions. Because there is no clear interpretation of the direct correlation functions it is not easy to judge the importance of the 


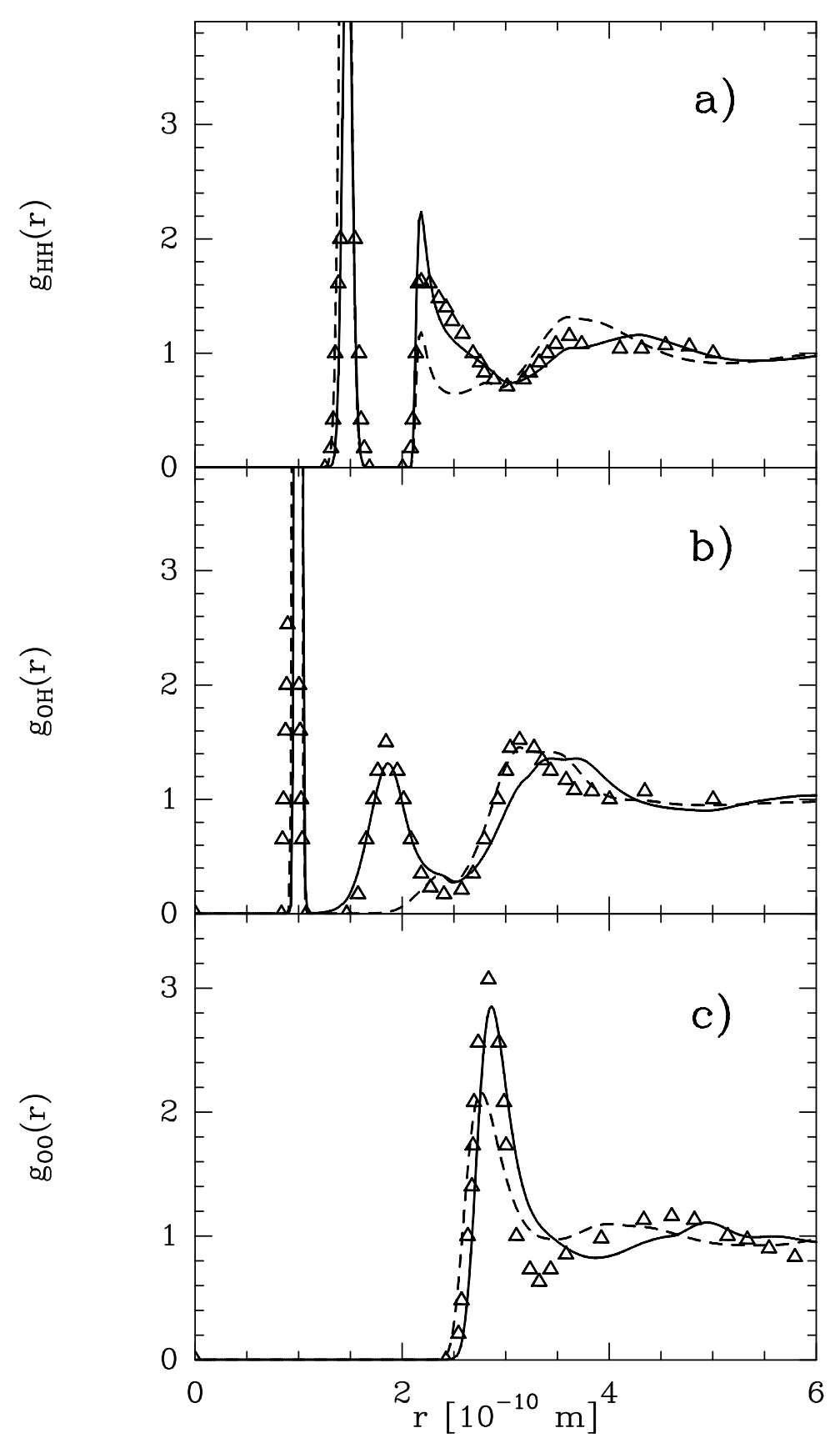

Figure 1. The pair distribution functions a) $g_{H H}(r)$, b) $g_{O H}(r)$, and c) $g_{O O}(r)$ for bulk water. Our calculation $(-)$, HNC approximation (- - ), MD results ([4]) (triangles). 
differences in $c_{\alpha \beta}(r)$. The particle densities $\rho_{\alpha}(z)$ (at a distance $z$ from the electrode surface) are calculated from an equation derivable by density functional arguments and first obtained by Wertheim [11] and Lovett, Mou, Buff [12]:

$$
\nabla_{1} \ln \rho_{\alpha}(1)=-\frac{1}{k_{B} T} \nabla_{1} V_{\alpha}(1)+\sum_{\beta} \int d 2 c_{\alpha \beta}(1,2 ;[\rho]) \nabla_{2} \rho_{\beta}(2) .
$$

This equation is exact, when the direct correlation functions in the inhomogeneous densities are employed. These are approximated by the functions

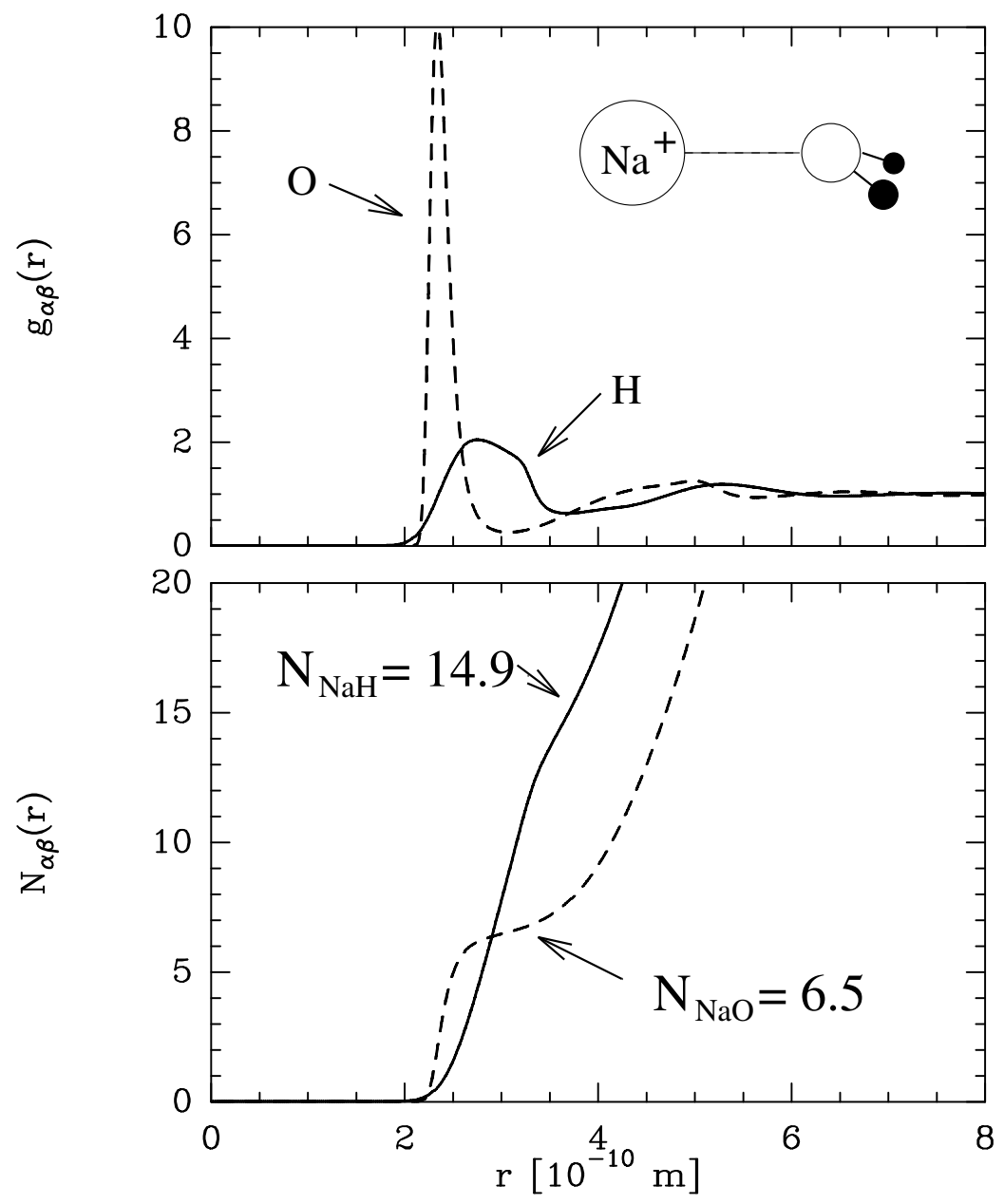

Figure 2. Pair distribution functions $g_{\mathrm{NaH}}(r)(-)$ and $g_{N a O}(r)$ (- - ) and running coordination numbers.

of the homogeneous bulk. In this approximation, equation (4) is simply the $\mathrm{z}$-derivative of the $\mathrm{HNC}$-equation at thesurface [see also 13]. The potential $V_{\alpha}(1)$ describes the interaction betweeen theelectrode and the particle of kind $\alpha$. We take

$$
V_{\alpha}(z)=V_{\alpha}^{S R}(z)-4 \pi q_{\alpha} \omega z
$$


for the electrode with a surface charge density $\omega$, particle charge $q_{\alpha}$ and the short range repulsive wall potential $V_{\alpha}^{S R}(z)=A / z^{9}\left(\mathrm{~A}=1.88 \times 10^{-14} \mathrm{erg}\right)$ equal for all particles. This repulsive wall potential is close to a hard wall and only more convenient in the numerical iteration procedure for solving equation (4). Further details of the calculation can be found in [1] and [2].
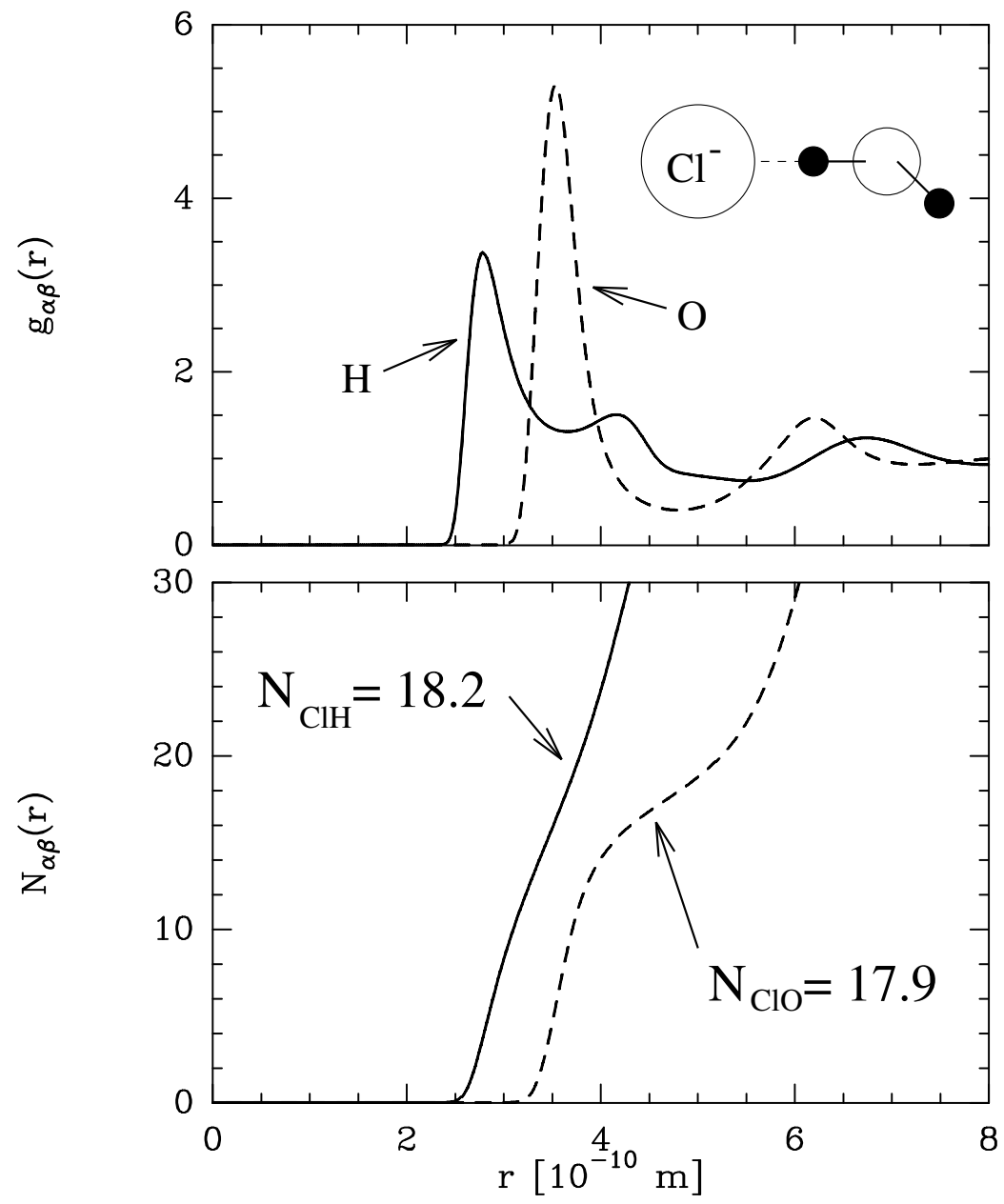

Figure 3. Pair distribution functions $g_{C l H}(r)(-)$ and $g_{C l O}(r)$ (- - ) and running coordination numbers.

First we study the interface of pure water. In figure 5 are plotted the densities of oxygen and hydrogen as well as the charge density $q(z)=$ $q_{H} \rho_{H}(z)+q_{O} \rho_{O}(z)=q_{H}\left(\rho_{H}(z)-2 \rho_{O}(z)\right)$ with $q_{H}=-\frac{1}{2} q_{O}=0.32983 e_{0}$. The charge density resolves the water structure near the surface into a double layer of oxygen (negative charges) followed by a double peak of hydrogens between 2 and $3.4 \AA$. A second repetition of this structure is not fully resolved. This sequence reminds of the ice-network which has been used previously for the interpretation of the structures found in simulations [14] and with multipole models [15]. We can imagine one of the double layers of tetrahedrally bonded water molecules [see figure 6] parallel to the wall, which is connected to the next double layer by hydrogen bonds normal to 
the surface. Because of the liquid disorder the hydrogens in the bonds inside the first oxygen double layer are barely seen, but it makes sense, that the first hydrogen peak at $2.3 A$ is higher than the second at $3 A$ : in bulk ice, half of the hydrogen will belong to the left double layer and half to the right, therefore the densities in the asymmetric hydrogen bond positions will be equal. Here all hydrogens of the contact water molecules have been turned

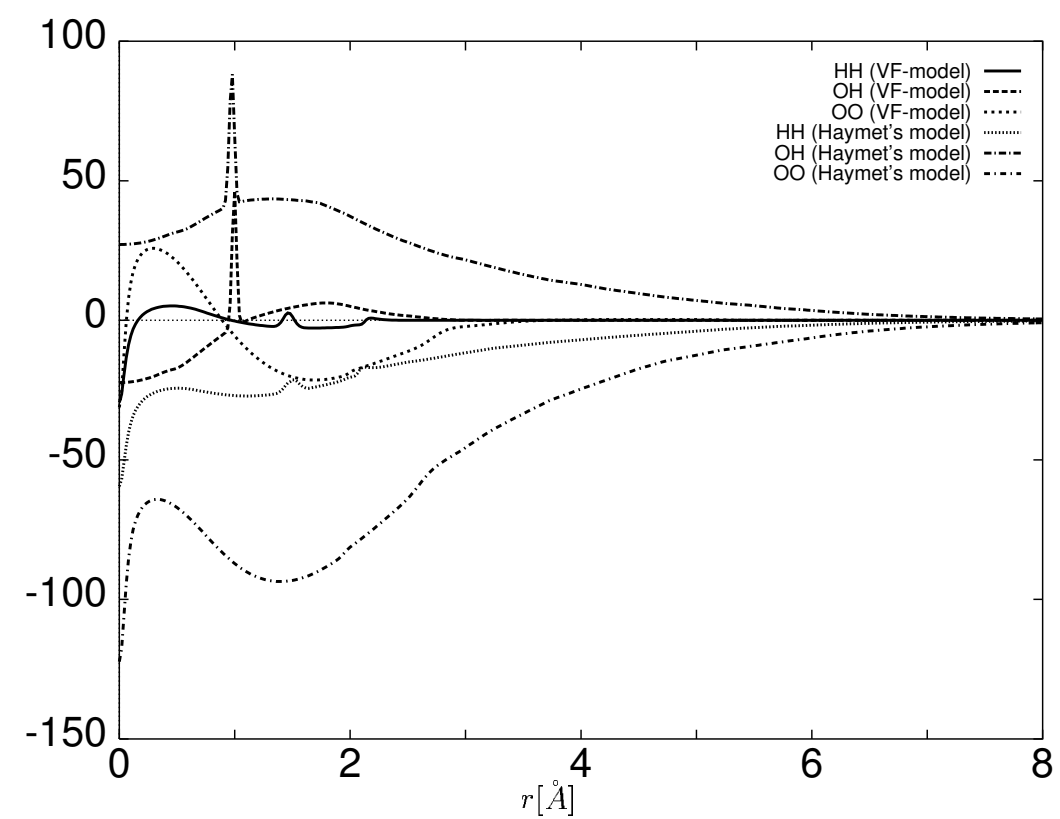

Figure 4. Direct correlation functions $c_{\alpha \beta}^{S R}(r)$ which are the bulk input for the surface calculation. Our functions and Haymet's curves [24].

towards the bulk liquid and consequently more hydrogens are pushed on the liquid side of the first double layer. This detailed structure in agreement with simulations [14] is a strong argument in favour of our integral equation calculation. Important consequences are: The water molecules at contact have their oxygens at the wall and their dipoles pointing towards the liquid. This results in a surface potential $\Psi(z=0)$ with

$$
\begin{aligned}
\Psi(z)-\Psi(\text { bulk }) & =\int_{b u l k}^{z}\left(-E\left(z^{\prime}\right)\right) d z^{\prime} \\
& -\int_{b u l k}^{z} d z^{\prime} \int_{b u l k}^{z^{\prime}} 4 \pi \rho\left(z^{\prime \prime}\right) d z^{\prime \prime}=4 \pi \int_{b u l k}^{z}\left(z^{\prime}-z\right) \rho\left(z^{\prime}\right) d z^{\prime} .
\end{aligned}
$$

Our charge distribution of figure 5 yields the surface potential $\Psi(z=0)-$ $\Psi(b u l k)=-0.11 \mathrm{~V}$. It should be noticed that the sign of the surface potential related to the surface dipole pointing towards the liquid is caused by the hydrogens all lowering their energy in hydrogen bonds and not by preferential adsorption of oxygen. It is therefore a property of the water surface structure and not of the interaction with the electrode. We have tested this concept by charging the surface. Especially for negative surface charge we find a reduced polarizability of the water structure, because the hydrogens stay in their bonds and do not turn towards the surface, until the 

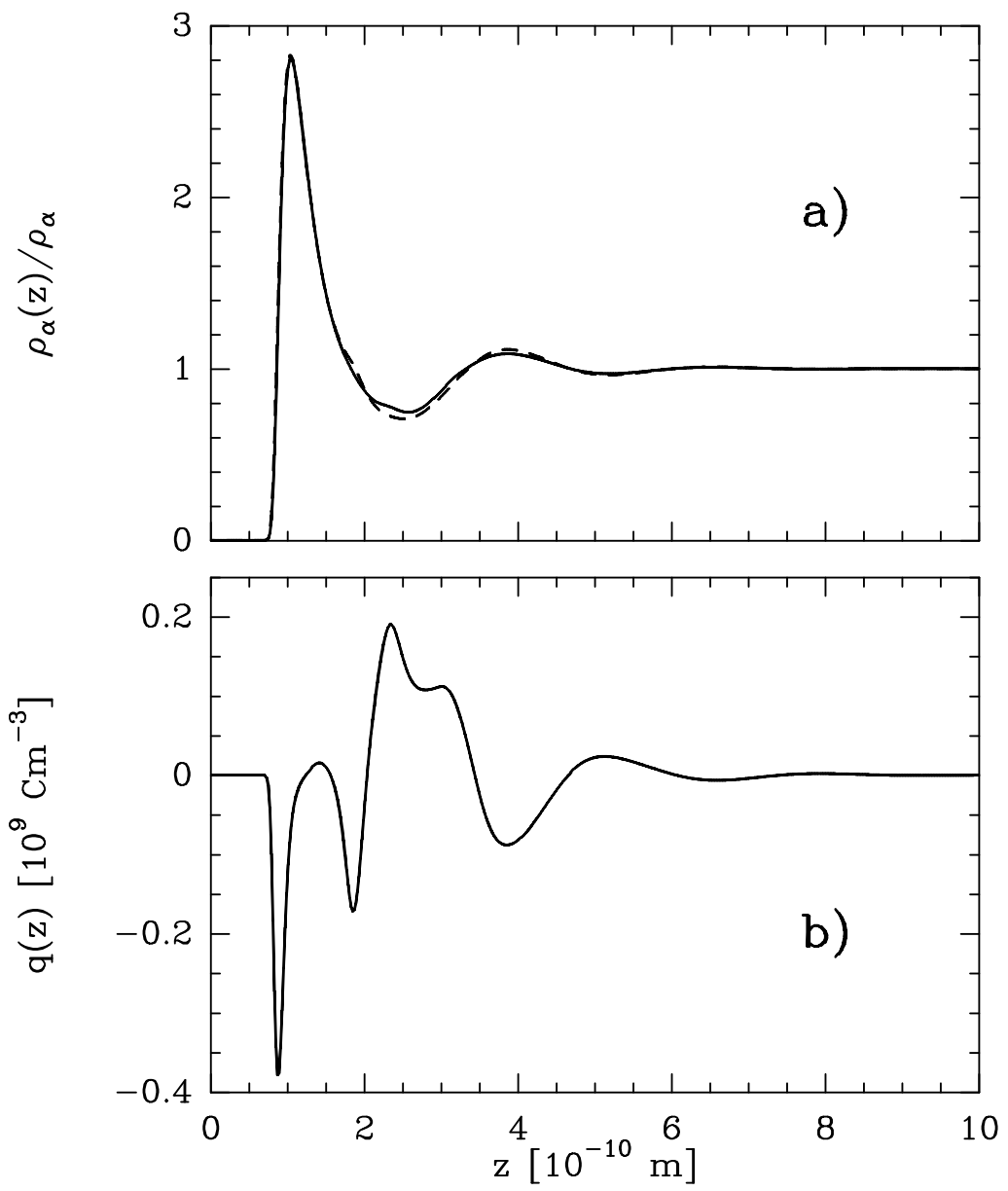

Figure 5. Density profile $\rho_{\alpha}(z)$ for hydrogen and oxygenand charge density $q(z)$.

field is strong enough to provide the same potential energy as the hydrogen bonds. By this mechanism the differential capacitance of the interface shows an asymmetry with a minimum at negative electrode charge solely due to the water interface structure [1]. We have also investigated surfaces with preferential oxygen attraction. This leads to an increase of the surface dipole and a more negative value of the surface potential [1]. The sign and the order of magnitude of this interface potential step is in agreement with experimental indication $[16,17]$ and other model calculations $[18,19,20,21]$. In this respect we are in disagreement with the results of Booth, Duh and Haymet $[22,23,24]$ who calculated for the same pure water model with only slightly changed interactions and different bridge functions in the bulk (see our figure 4 ). They derive a surface dipole with opposite sign and a surface potential $\Psi(z=0)=+0.6 \mathrm{~V}$. We are presently investigating the reasons for this discrepancy. 


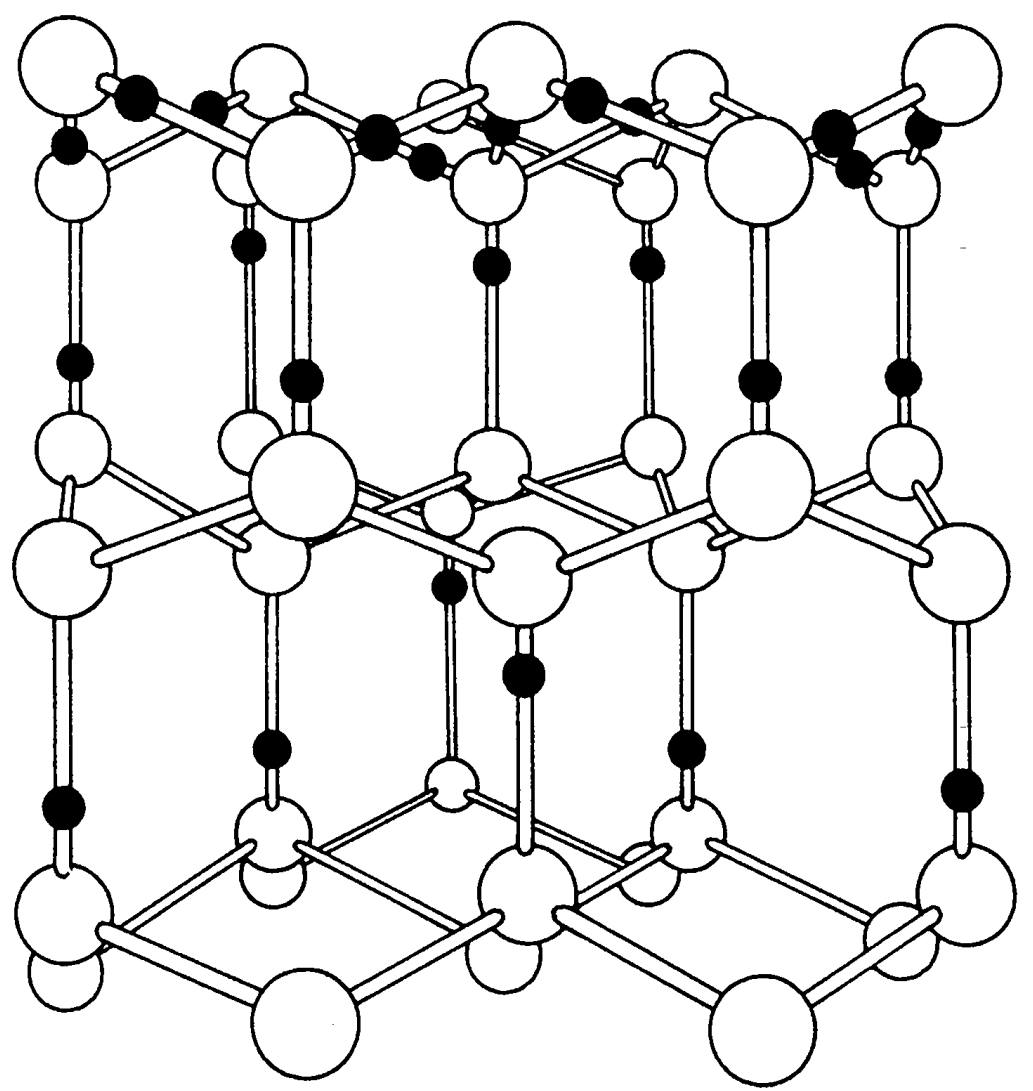

Figure 6 . The ice-1c structure. Not all hydrogens are shown.

\section{The electrolyte at the hard wall}

Figure 7 shows the densities near the interface for the 0.01 molar $\mathrm{NaCl}$ solution at the uncharged electrode. The water structure is obviously only weakly perturbed and the ions have to adapt to this structure. The smaller $\mathrm{Na}^{+}$ions penetrate further than $\mathrm{Cl}^{-}$, but neither can really enter the first double layer of netted water molecules. There is some displacement of hydrogen atoms leading to a little screening of the surface dipole yielding a potential step of $\Psi(z=0)-\Psi$ (bulk $)=-74 \mathrm{mV}$. The dipole potential is again determined by the water structure with negative oxygen closest to the wall and the hydrogens fixed in hydrogen bonds, pointing towards the liquid. This value of $\Psi(z=0)$ should not be mixed up with the potential of zero charge (PZC), which is the difference between the Fermi levels of the uncharged electrode and a standard reference electrode (see [2]). These density distributions give an impression a little different from the folklore about ions in the double layer. The ions penetrate into the water structure and are not migrating with their individual solvation shells. "Solvation" is achieved by pushing around the hydrogens in the hydrogen bonds, which can be interpreted as a reorientation of dipoles.

We have charged the electrode and attracted the ions towards the surface 

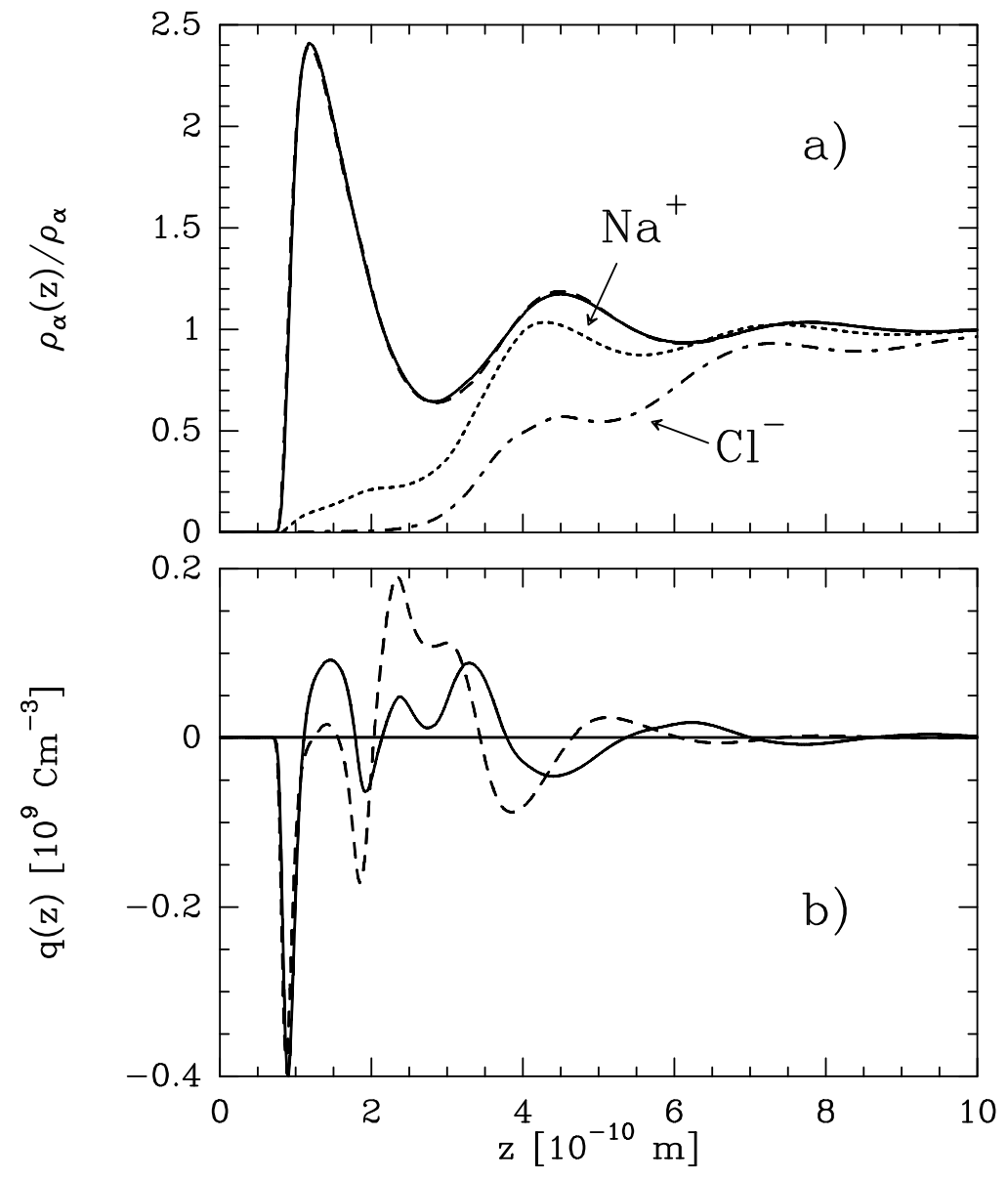

Figure 7. a) The density profiles $\rho_{\alpha}(z)$ for the electrolyte at the uncharged electrode. b) The charge density $q(z)$ of the water water solvent (-) and for pure water (- -).

(figure $8 \mathrm{a}$ and figure $8 \mathrm{~b}$ ). At smaller charges the ion penetration is still suppressed by the water structure. The small $\mathrm{Na}^{+}$ions finally invade the first double layer of the water structure. It is interesting to notice, that this penetration is connected with the increase of the polarizability of the water due to the hydrogens turning towards the wall, when the field is strong enough to provide the same energy gain as the hydrogen bonds. The hydrogens obviously move out and the $\mathrm{Na}^{+}$move into the first water double layer when the surface charge is increased beyond $-3.7 \mu \mathrm{C} / \mathrm{cm}^{2}$. This mechanism is supported by the experimental and theoretical finding of a maximum of the interfacial entropy for surface charge densities in the range from -4 to $-6 \mu \mathrm{C} / \mathrm{cm}^{2}$ [25] when according to our calculation the hydrogens of the contact water molecules can occupy two different positions, the hydrogen bond or the bond pointing towards the surface.

The $\mathrm{Cl}^{-}$ions do not follow the attractive field [figure 8b] because they appear too large in our model. The water structure expels them. We are reconsidering our model parameters for the $\mathrm{Cl}^{-}$interactions, because 
our calculation at present does not show the specific adsorption which was so often derived for chlorine. But this problem is also seen in computer simulations. [26]
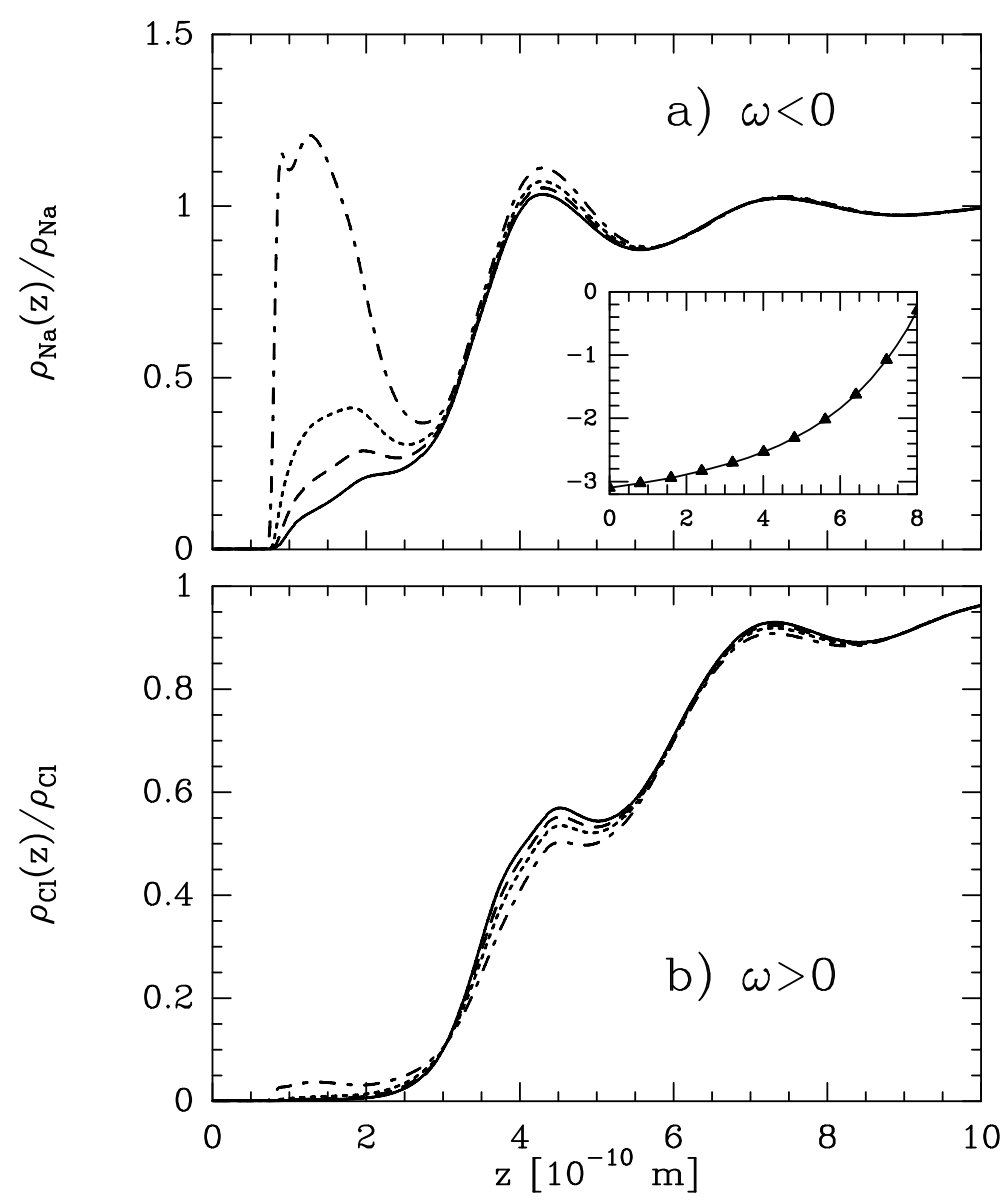

Figure 8. Denstity of $\mathrm{Na}^{+}$at the negatively charged "hard" wall (a) and $\mathrm{Cl}^{-}$at the positively charged "hard" wall (b). The charges: $\omega=0(-), \omega= \pm 1.66, \pm 3.2, \pm 6.4(\cdots)$ $\mu \mathrm{C} / \mathrm{cm}^{2}$. Inset: Surface excess of $\mathrm{Na}^{+}$as function of $-\omega$.

We have again calculated the differential capacitance and found the asymmetric minimum essentially at the same negative charge $(\omega=-4$ $\left.\mu \mathrm{C} / \mathrm{cm}^{2}\right)$ as for pure water which again can be attributed to the water structure (see figure 9 ).

\section{Conclusions}

The central force water model is especially well suited for use in integral equations of statistical mechanics. At an electrode it produces a hydrogen 
bounded ice structure with a surface dipol pointing towards the liquid and a differential capacitance asymmetry with a minimum at negative electrode charge. $\mathrm{Na}^{+}$and $\mathrm{Cl}^{-}$ions have to penetrate this structure. The small $\mathrm{Na}^{+}$ is sucessful at higher negative electrode charge while $\mathrm{Cl}^{-}$is expelled. Also for the electrolyte the surface potential at zero electrode charge and the asymmetry of the capacitance is determined by the water structure.

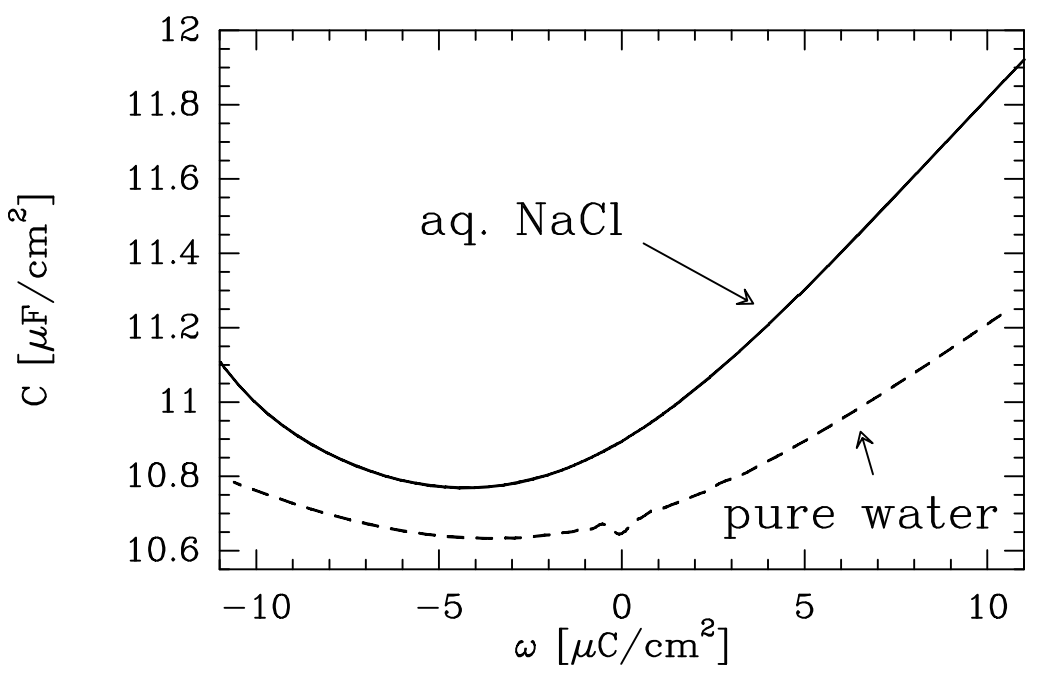

Figure 9. Differential capacitance $C=\partial \omega / \partial \Psi$ vs $\omega$.

\section{References}

[1] Vossen M., Forstmann F. // J. Chem. Phys., 1994, vol. 101, p. 2379.

[2] Vossen M., Forstmann F. // Mol. Phys., (in press).

[3] Lemberg H.L., Stillinger F.H. CEntral-forces model for liquid water. // J. Chem. Phys., 1975, vol. 62, No 5, p. 1677-1690.

[4] Stillinger F.H., Rahman A. Revised central force potentials for water. // J. Chem. Phys., 1978, vol. 68, No 2, p. 666-670.

[5] Rahman A., Stillinger F.H., Lemberg H.L. Study of a central force model for liquid water by molecular dynamics. // J. Chem. Phys., 1975, vol. 63, No 12, p. $5223-5230$.

[6] Kistenmacher H, Popkie H., Clementi E. Study of structure of molecular compexses V. Heat of formation of the $\mathrm{Li}^{+}, \mathrm{Na}^{+}, \mathrm{Ka}^{+}, \mathrm{F}^{-}$and $\mathrm{Cl}^{-}$ion complexes with a single molecule. // J. Chem. Phys., 1973, vol. 59, No 11, p. 5842-5848.

[7] Pettitt B.M., Rossky P.J. // J. Chem. Phys., 1986, vol. 84, p. 5836.

[8] Smith D.E., Haymet A.D.J. // J. Chem. Phys., 1992, vol. 96, p. 8450.

[9] Thuraisingham R.A., Friedman H.L. HNC Solution for the central force model for liquid water. // J. Chem. Phys., 1983, vol. 78, No 9, p. 5772-5784.

[10] Ichiye T., Haymet A.D.J. Accurate integral equation theory for the central force model of liquid water and ionic solutions. // J. Chem. Phys., 1988, vol. 89, No 7, p. 4315-4326.

[11] Wertheim M.S. Correlation in the liquid-wapour iterface. // J. Chem. Phys., vol. 65, No 6, p. 2377-2381.

[12] Lovett R., Mou C.Y., Buff F.P. // J. Chem. Phys., 1976, vol. 65, p. 570.

[13] Henderson D., Blum L. // J. Chem. Phys., 1989, vol. 93, p. 4303. 
[14] Lee C.Y., McCammon J.A., Rossky P.J. The structure of liquid water at an extended hydrophobic surface. // J. Chem. Phys., 1984, vol. 80, No 9, p. 4448-4455.

[15] Torrie G.M., Kusalik P.G., Patey G.N. Molecular solvent model for an electrical double layer: Reference hypernettted-chain (RHNC) results for solvent structure at a charged surface. // J. Chem. Phys., 1988, vol. 88, No 12, p. 7826-7840.

[16] Thiel P.A., Madey T.E. // Surf. Sc. Reports, 1987, vol. 7, p. 211.

[17] Gomer R., Tyson G. An Experimental determination of absolute half-cell empf's and single ion free energies of solvation. // J. Chem. Phys., 1977, vol. 66, No 10, p. 4413-4424.

[18] Valleau J.P., Gardner A.A. Water-like particles at surfaces 1. The uncharged, unpolarised surface. // J. Chem. Phys., 1987, vol. 86, No 7, p. 4162-4170.

[19] Torrie G.M., Patey G.N. // J. Phys. Chem., 1993, vol. 97, p. 1290.

[20] Aloisi G., Foresti M.L., Guidelli R. A Monte Carlo simulation of water molecules near a charged wall. // J. Chem. Phys., 1989, vol. 91, No 9, p. $5592-5596$.

[21] Hautman J., Halley J.W., Rice Y.J. Molecular dynamics simulation of water between two ideal classical metall walls. // J. Chem. Phys., 1989, vol. 91, No 1, p. 467-476.

[22] Booth M.J., Duh D.M., Haymet A.D.J. // J. Chem. Phys., 1994, vol. 101, p. 7925 .

[23] Haymet A.D.J. // Journal of Molecular Liquids (in press).

[24] Duh D.M., Perera D.N., Haymet A.D.J. // J. Chem. Phys., 1995, vol. 102, p. 3736 .

[25] Guidelli R. Trends in Interfacial Electrochemistry. Dordrecht, Reidel, 1986, p. 387.

[26] Spohr E. // Chem. Phys. Lett., 1993, vol. 207, p. 214 and private communication.

\title{
ЦЕНТРАЛЬНОСИЛОВА МОДЕЛЬ ВОДИ ПРИ МЕЖІ ЕЛЕКТРОЛІТ-ЕЛЕКТРОД: МЕТОД ІНТЕГРАЛЬНИХ РІВНЯНЬ
}

\author{
М.Фоссен, Ф.Форстман, А.Кремер
}

\begin{abstract}
Шентральносилова модель є дуже зручною для застосування у методі інтегральних рівнянь. На поверхні електрода молекули води виявляються розміщеними так, що утворюеться структура типу льоду з поверхневим диполем, спрямованим до рідини й негативним поверхневим потенціалом $-0.11 \mathrm{~V}$ при нульовому зарядові електрода. Ми знайшли асиметричну диференціальну ємність зумовлену такою структуроюводи. Додані іони $\mathrm{Na}^{+}$ та $\mathrm{Cl}^{-}$не руйнують цієі структури. Лише мала кількість $\mathrm{Na}^{+}$ може проникати в структурований шар води при високому негативному заряді електрода.
\end{abstract}

